Discussion

\title{
The Significance of the Pech Merle Spotted Horses
}

\section{Derek Hodgson}

Research Associate, Dept. of Archaeology, University of York, York, YO1 7EP, UK;

E-Mail: dehogson@gmail.com; Tel.+44 1-904-633834.

Received: 7 March 2014; in revised form: 10 April 2014 / Accepted: 28 April 2014 /

Published: 8 May 2014

\begin{abstract}
The Pech Merle spotted horses have been one of the key lines of evidence put forward in support of the notion Upper Palaeolithic cave depictions relate to a concern for the supernatural. Recent findings from genetics has cast doubt on this notion in confirming that such horses actually existed during the Upper Palaeolithic in Europe and therefore it is possible real, rather than fictitious, horses were being portrayed. As well as examining criticisms in response to this finding, the present paper presents further evidence to support the possibility real horses were portrayed and the implications for explanations that continue to rely on the supernatural.
\end{abstract}

Keywords: Pech Merle; cave art; genetics; horses; visual science; Palaeolithic

\section{Introduction}

Pruvost and associates' [1] finding that the leopard horses of Pech Merle depict real equines casts doubt on the claim they are associated with the supernatural, but provides support for earlier claims that Upper Palaeolithic hunter-gatherers were keen observers of animals [2, 3, 4]. Reaction to the fact these horses actually existed during the Upper Palaeolithic in Europe has, however, been mixed with supporters of the supernatural explanation emphasising that the Pech Merle equines represent but one instance of the many horses depicted (Clottes quoted in Knight, [5] [6]). Notwithstanding these criticisms, Pruvost and co-workers [1, 5, 7] insist that, as spotted horses existed during the Upper Palaeolithic, this supports the notion real horses were being portrayed. 


\section{Ascertaining Veracity}

In order to ascertain the veracity of these conflicting claims, it may be useful to follow the rule of parsimony, which stipulates that a complex explanation should not be adopted if a simpler, more straightforward description can account for a phenomenon. Thus, a reliance on the magical often occurs when robust scientific evidence to the contrary is lacking. This would also apply to the shamanistic account [8, 9]. In fact, Lewis-Williams [9], one of the original instigators of the neuropsychological model, placed great reliance on the Pech Merle spotted horses in support of the shamanistic interpretation, where the painted spots were suggested to be copies of phosphenes (phantom spots seen in the mind's eye) caused by altered states of consciousness. However, as LewisWilliams [9] stated, the outlines of the horses were drawn first after which the spots were then added, which is opposite to the neuropsychological model that predicts the spots should have been depicted first. As it is now clear spotted horses existed during the Upper Palaeolithic, it would therefore seem parsimonious to regard the Pech Merle equines as depictions of real horses, which challenges shamanism as a plausible explanation. This is supported by the Pruvost et al. [1] finding that brown and black horses also existed during the Upper Palaeolithic and are depicted throughout Ice Age cave art, which, therefore, contradicts the "one off" accusation of Clottes mentioned above. In addition, brown and black herbivores were depicted in a realistic manner to the extent that their winter and summer pelage and characteristic behaviour are identifiable [10].

The defence that some of the painted spots extend beyond the contours of the actual horses and are, therefore, not realistic [5,6] can also be explained more routinely. First, it should be noted that the majority of the spots are located within the outlines of the two horses portrayed. Second, the exterior spots follow the contour outlines of the horses with the spots of the right horse seeming to make a third larger and quite naturalistic horse, which can be observed when the contour outlines are removed (compare Figures 1 and 2). In fact, if we are to accept that the spots represent phosphenes (or entoptics), we would expect them to be arranged in a much more haphazard manner, but this is not the case. Third, and as Hodgson [11] states "... the spots of the Pech-Merle horses seem to be larger than one would expect on natural horses but this may be a result of the fact that exaggeration of significant features of animals is common in cave art due to the fact that these would have loomed large in the mind's eye of the hunters concerned." The spots, which were mostly created by blowing pigment through the mouth, could therefore be another example of the exaggeration of a key feature that produces a stimulating visual effect. The spots extending beyond the contours can thus be regarded as a super-stimulus, especially as spotted white horses would have stood out from the more common black and brown equines. It is also pertinent spotted white pelage would have provided better camouflage in the wintry conditions of the Ice Age. 
Figure 1. The Pech Merle leopard spotted horses (www.slideshare.net/extremecraft/01paleolithic).

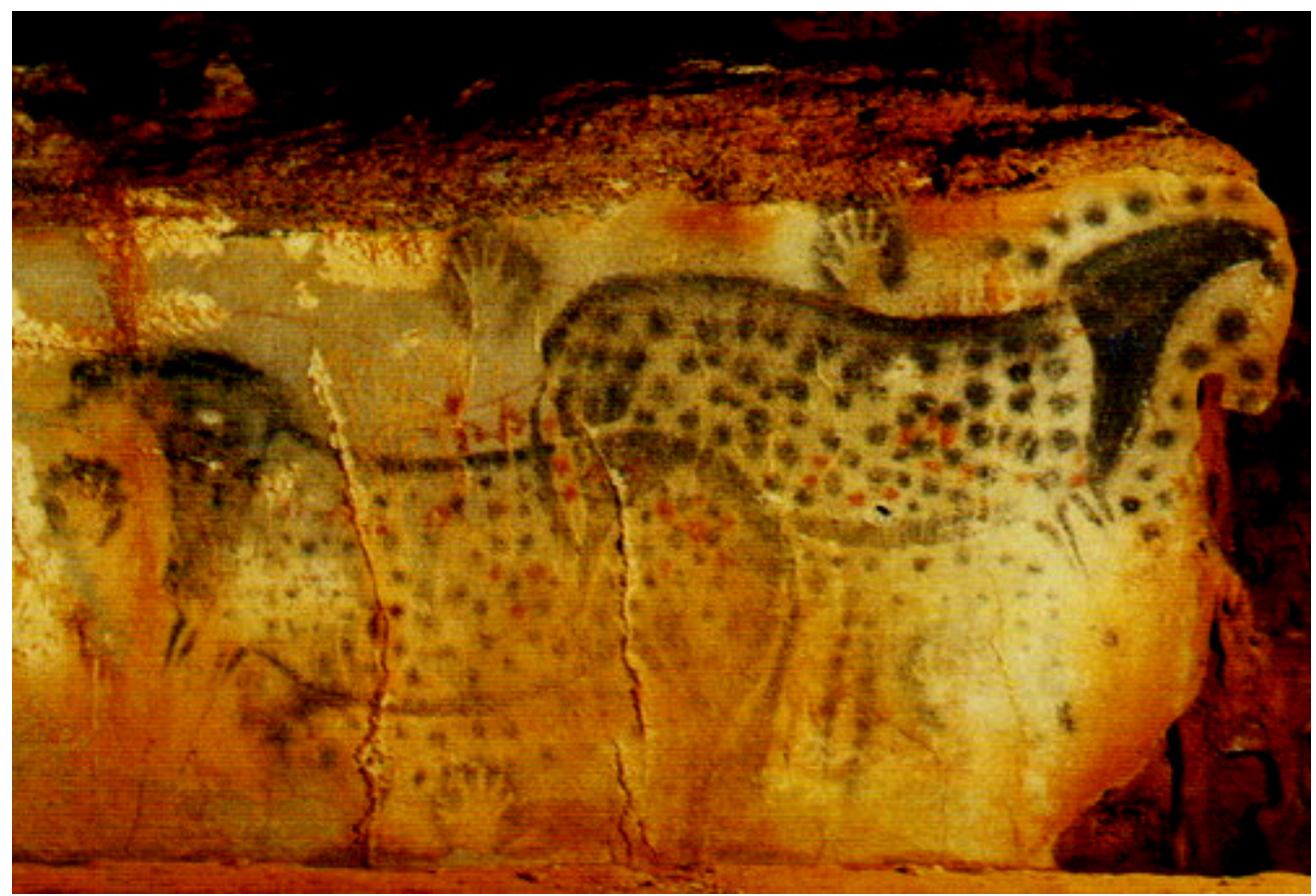

Figure 2. The Pech Merle leopard spotted horses with outlines removed.

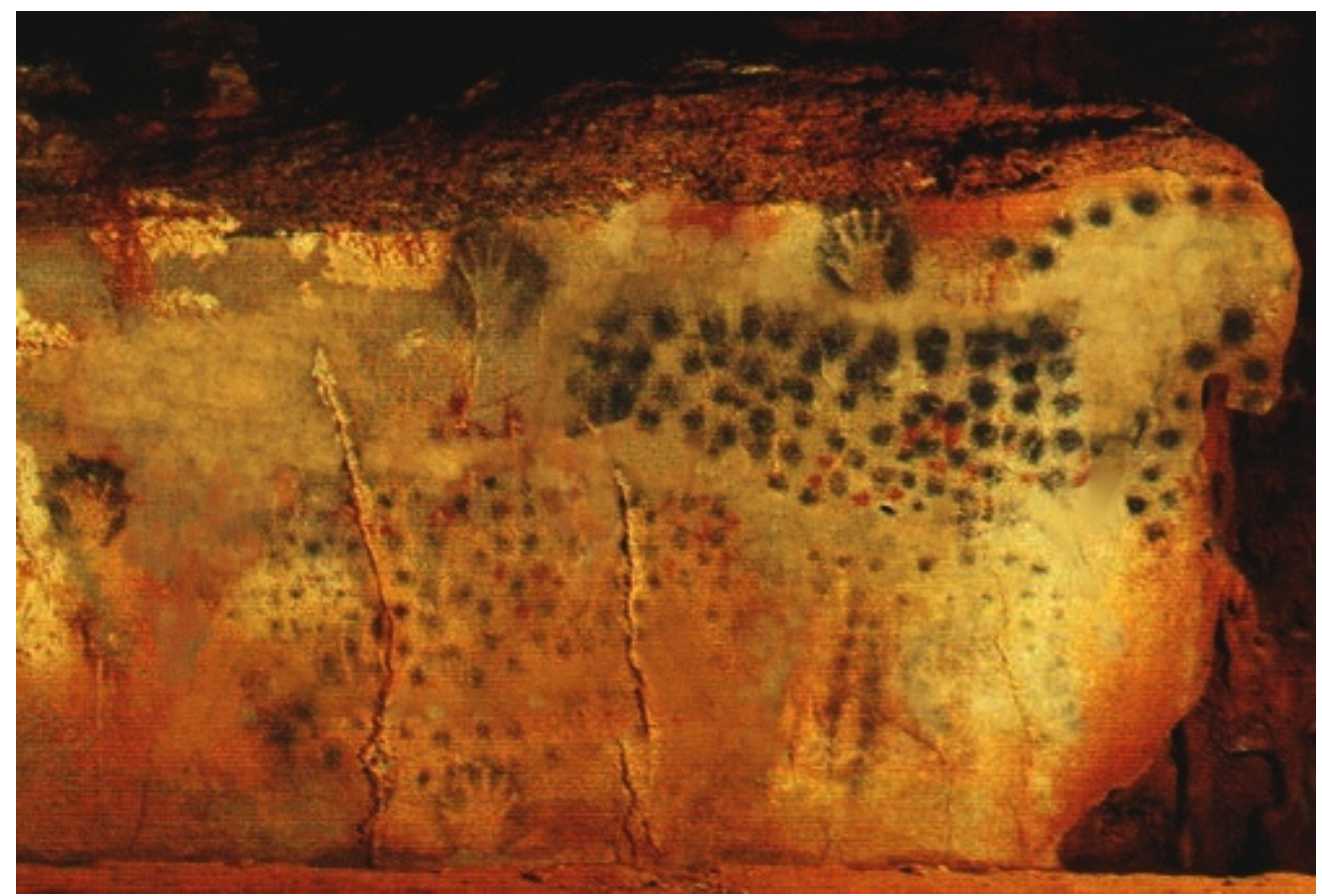

Alpert [6] makes the further interesting observation that spots can be found on depicted animals in Upper Palaeolithic art not known to have dappled pelage. Interestingly, most of the spots Alpert refers to are red (a few of the spots on the Pech Merle horses are also red). Although Guthrie's all-encompassing theory on palaeoart has been criticised, he makes the interesting observation [12, $\mathrm{p}$. 270] that red spots may represent animal wounds or blood on the ground issuing from injured animals, 
which are useful for tracking and are particularly salient in snow. Guthrie, himself a hunter, has noted that tracking the blood of wounded animals over a prolonged period subsequently leads to involuntary images of such features appearing in the mind's eye sometime after the hunt (Hodgson [13] refers to these as hyperimages). In fact, the red spots depicted on the right horse at Pech Merle are primarily located within the chest region, the most propitious anatomical area for disabling a herbivore with a spear [12, p. 281]. Similarly in the case of the red dots of the left hand horse, most of these are located in positions that would have inflicted serious injury. Interestingly, Igarashi [14] found a strong correlation between $\mathrm{V}$-shaped signs and the hit marks necessary for disabling quarry that suggest such signs may represent actual weapons.

Lorblanchet [15] has documented the sequence by which the graphic features were drawn on the horse panel at Pech Merle, which is highly informative as to derivation. One of the initial marks made on the panel is a red "hook" shape on the right horse's muzzle. It is notable that this mark appears on the protruding natural feature that resembles a horse's head. Such natural shapes seem to have been an important initial stimulus leading to the creation of animal depictions (yet another hyperimage as defined by Hodgson [13]). The placing of the hook shape on this natural feature could have been a means of calling attention to the natural resemblance after which the outlines of the two horses were completed. As already noted, it was only after the outlines of the horses had been drawn that the black spots (212 altogether) were added, although the hand stencils and a red arch like feature (which could have been made by a different individual[s]) were created after the outlines but before the spots. This sequence of events accords with the way the human visual system prioritises information for the purpose of perception $\rightarrow$ recognition where the contour outline is identified first after which the interior details are then "filled in", including camouflage pelage e.g., dapples [3, 2013]. It is therefore reasonable to propose that many of the features of the spotted horses can be explained by the functioning of the visual/perceptual system. It is also notable that the twenty nine red dots were inserted subsequently to the completion of the horse contours and black spots, which is consistent with the red dots depicting wounds.

Of course, such perceptual factors were not reflected in all aspects of the depicted Pech Merle horses, as cultural imperatives would also have intervened. The repetition of the same motif in religions throughout the world is associated with ritual; similarly, repeated representations of the same animals is a key feature of Upper Palaeolithic cave art, in some cases where the animal outlines underwent so much superimposition the animals are often difficult to discern - a phenomenon that can also be found at Pech Merle and may therefore relate to some form of ritual activity. In addition, there are indications in many of the caves of ritual-like activities, such as bones fragments intentionally placed in crevices [8] as well as the deliberate defacing of animal outlines. The rituals of huntergatherers are invariably imagistic in format and are associated with intense emotional experiences usually involving physical stress and psychologically disturbing acts that encourage long-term reflection on the mystical significance of the "art" utilized [17]. In the case of cave art, this may have involved a dangerous and physically challenging quest by selected individuals to search for and depict such images, i.e., hyperimages. This suggests ritual behaviour may have been associated with the spotted horses but its exact nature continues to remain unclear. 


\section{Discussion}

The lesson from Pruvost and associates' finding should therefore be that caution is advisable when resorting to exotic explanations to explain Upper Palaeolithic Art. The genetic evidence, as well as the data from visual science, provides a relatively reliable starting point for determining whether any extra level of meaning was accorded to the depicted animals. However, as the genetic evidence and visual science suggest the spotted horses can be explained without the need to resort to exotic narratives, it is up to those who support supernatural accounts to provide a similar calibre of evidence by way of corroboration. Ultimately, the two approaches need not be diametrically opposed as the relative scarcity of spotted horses during the Upper Palaeolithic may well have led to Cro-Magnons granting special status to such equines. This suggests that the realistic/naturalistic representations of animals in Upper Palaeolithic cave art were interwoven with ritualistic behaviour in ways that continue to remain inscrutable.

\section{Conclusion}

The response of archaeologists specialising in palaeoart to the genetic evidence regarding the Pech Merle horses has generally been negative in that the depictions are regarded as a "one-off" and therefore do not qualify as proof, or that spots can be found on a number of animals not known to be dappled and spots are not always depicted within the anatomy of the animal concerned. However, the genetic evidence, and I would submit the insights of visual science, cannot simply be dismissed as anomalous. In fact, archaeologists were quite satisfied to forefront the Pech Merle horses as a "oneoff' in support of the shamanic trance account, but are only too ready to disqualify an appeal to the same depictions when this contradicts such a model. As tangible evidence that can inform us as to the nature of Upper Palaeolithic cave art remains scarce, when such evidence becomes available it behoves the archaeological community to take a more positive stance towards integrating such findings into their models.

\section{Conflicts of Interest}

The author declares no conflict of interest

\section{References}

1. Pruvost, M.; Bellone, R.; Benecke, N.; Sandoval-Castellanos, E.; Cieslak, M.; Kuznetsova, T.; Morales-Muñiz, A.; O’Connor, T.; Reissmann, M.; Hofreiter, M.; Ludwig, A. Genotypes of Predomestic Horses Match Phenotypes Painted in Paleolithic Works of Cave Art. Proc. Natl. Acad. Sci. USA 2011, 108, 18626-18630; pp. 1-5.

2. Guthrie, R. D. Ethologicial Observations from Palaeolithic Art. In La Contribution de la Zoologie et de L'Ethologie à L' Interpretation de L'Art des Peuples Chasseurs Préhistoriqùes: 3 e Colloque de la Société Suisse des Sciences Humaines (1974). Bandi, H., Huber, W., Sauter, M. R., Bitter, S. Eds.; Éditions Universitaires Fribourg: Fribourg, Switzerland,1984; pp. 35-74. 
3. Hodgson. D. The Biological Foundations of Upper Palaeolithic Art: Stimulus. Percept and Representational Imperatives. Rock Art Research. 2003, 20; pp. 3-22.

4. Packer, G., Clottes, J. When Animals Ruled France Natural History. 2000, 109; pp. 52-57.

5. Knight, B. Pech Merle Horses Really Were Spotted, Scientists Say. Deutsche Welle, November, 2011. Available online: http://www.dw.de/pech-merle-horses-really-were-spotted-scientistssay/a-15517588 (accessed 10 September 2013).

6. Alpert, B.O. The Meaning of the Dots on the Horses of Pech Merle. MDPI Arts 2013, 2; pp. 476-490.

7. Ludwig, A., Pruvost, M., Bellone, R., Benecke, N., Sandoval-Castellanos, E., Morales-Muñiz, A., O’Connor, T., Reissmann, M., M. Hofreiter, M. Reply to Bar-Oz and Lev-Yadun: Horse Colours in Time and Space. Proceedings of the National Academy of Sciences of the United States of America 2012, 109; p. E1213.

8. Clottes, J. Why Did They Draw in Those Caves? Time and Mind. 2013, 6; pp.1-14.

9. Lewis-Williams, J. D. Wrestling with Analogy: A Methodological Dilemma in Upper Palaeolithic Art Research. Proceedings of the Prehistoric Society. 1991, 57; pp. 149-I62.

10. Bahn, P., Vertut. J. Journey Through the Ice Age; Weidenfeld and Nicolson: London, 1997.

11. Hodgson, D. On cognitive palaeontology and the infamous 'spotted' horse. Interview with Taylor Burns in Nature Education by SCITABLE November, 2011. Available online: http://www.nature.com/scitable/blog/cognoculture/on_cognitive_palaeontology_and_the (accessed 10 September 2013)

12. Guthrie, R. D. The Nature of Palaeolithic Art; University of Chicago Press: Chicago, 2005.

13, Hodgson, D. The Visual Dynamics of Upper Palaeolithic Art. Cambridge Archaeological Journal. 2008, 18; pp. 341-353.

14, Igarashi, J. Geometric Signs in Western European Palaeolithic Cave Art: Angular Signs (VShaped Angular Sign, Inverse V-Shaped Angular Sign, Arrow-Shaped Angular Sign). Bulletin of the International Jomon Culture Conference (Tokyo). 2006, 2; pp.127-138.

15. Lorblanchet, M. Art Pariétal: Grottes Ornées du Quercy; Editions du Rouergue: Rodez, France, 2010.

(C) 2014 by the authors; licensee MDPI, Basel, Switzerland. This article is an open access article distributed under the terms and conditions of the Creative Commons Attribution license (http://creativecommons.org/licenses/by/3.0/). 